\title{
Leadership \& Professional Development: Make the Most of Your Oranges
}

\author{
Josué Zapata, MD, MBA ${ }^{1,2 \star}$, Calvin Chou, MD, $\mathrm{PhD}^{1}$ \\ ${ }^{1}$ Department of Medicine, University of California, San Francisco, San Francisco, California; ${ }^{2}$ Division of Hospital Medicine, San Francisco VA Health \\ System, San Francisco, California.
}

"If you define the problem correctly, you almost have the solution."

-Steve Jobs

In the classic tale of a chaotic kitchen before an important dinner, two feuding chefs urgently need the only remaining orange in the pantry for their respective dishes. The first chef asserts its necessity for his prized sauce. The second chef retorts that her dessert will be ruined without it. After an emotion-laden battle, they finally agree to compromise, cutting the orange in half. The first chef squeezes the juice out of his half of the orange for his sauce, while the second grates half the zest she needs for her cake. Each chef had less of the orange than their recipe needed, but figured this was the best they could do given the dispute.

Conflict frequently occurs for hospitalists leading change efforts, managing service lines, and caring for patients. Often conflict can help clarify a decision or course of action. However, when navigated poorly, disputes can also consume precious energy and sap the goodwill and cooperation needed to effectively lead change and ensure excellent clinical care. Worse yet, ineffective conversations can result in begrudging and ultimately value-destroying agreements, as the chefs above demonstrate.

Instead of focusing on someone's position (the need for the orange), successful leaders first seek to understand all discernible underlying interests (zest, juice) and motivations (creating a signature dish) of each party. ${ }^{1}$ Essential to this process is swift recognition of the conflict and self-regulation. Rather than succumbing to strong fight-or-flight reactions, the wise hospitalist first takes inventory of their own interests and calmly applies a known schema, similar to their approach to common clinical scenarios.

So how can you get to the underlying interests effectively? We use a three-step process reminding us of the benefits of the orange's ACID. ${ }^{2}$

\section{ASK TO DISCOVER INTERESTS}

Ask open-ended questions and closely listen to their responses. Listening more than talking is critical to this process. When facing conflict, it is common to listen only to refute the other's position. Instead, actively suppress your instinct to "reload" and seek to genuinely understand the other's perspective.

*Corresponding Author: Josué Zapata, MD, MBA; e-mail: Josue.Zapata@ucsf. edu; Telephone: 415-221-4810; Twitter: @josuezapata

Received: June 14, 2019; Accepted: June 14, 2019

(c) 2020 Society of Hospital Medicine DOI 10.12788/jhm.3267
Continue to ask clarifying questions until you feel you understand their interests.

A new hire requests a higher salary than offered. Ask with curiosity: "Can you tell me more about some of your financial priorities? Even if I can't do much about the dollar figure, there may be benefits and other helpful tips I can suggest."

\section{CHECK YOUR UNDERSTANDING}

Restate your understanding of their interests from listening. This critical step serves to confirm your good-faith effort to address a common problem and to demonstrate that you have heard their perspective accurately. Even if you ultimately cannot agree on a solution to the dispute at hand, demonstrating an understanding of their perspective helps to preserve the relationship, which can be useful for future conflicts.

"I am hearing that you are hoping to save money for the future, to pay down outstanding loans, and to expand your family. Is that right?"

\section{IDENTIFY SOLUTIONS TOGETHER}

Accurately defining interests and demonstrating your understanding will maximize the possibility of mutually acceptable solutions. Share your own perspective, being careful to describe your underlying interests, not positions. What mutual goals do you share? What potential solutions were not immediately evident based on positions alone? During this process, remain open to arriving at a solution that you had not anticipated.

"While I unfortunately have little wiggle room on annual salary, there are some options for loan repayment, housing down payment assistance, and low-cost childcare at the health system, which is where my kids went."

Whether you are a chef or a hospitalist and whether you are dividing oranges or clinical shifts, understanding the interests buried within the conflict will help define and potentially solve the problem. When you encounter an orange, remember the value of its ACID.

\section{References}

1. Fisher RL., Ury A, Patton B. Getting to Yes. Penguin Books, 2011.

2. Adapted from: Chou CL, Cooley L. Communication Rx. McGraw Hill, 2018.

\section{Acknowledgement}

The authors wish to thank Charlie Wray, DO, Division of Hospital Medicine, San Francisco VA, for assistance with revisions of early drafts.

Disclosures: Dr. Zapata has no relevant conflicts of interest to report. Dr. Chou reports personal fees from Academy of Communication in Healthcare, other from McGraw Hill, outside the submitted work. 